\title{
Instruments of identification of hydraulic components potential failures
}

\author{
Joanna Fabiś-Domagała ${ }^{1,}{ }^{*}$, Grzegorz Filo ${ }^{2}$, Hassan Momeni ${ }^{1}$, and Mariusz Domagała ${ }^{1}$ \\ ${ }^{1}$ Cracow University of Technology, Institute of Applied Informatics, Al J. Pawla II 37, \\ 31-841 Cracow, Poland \\ ${ }^{2}$ Western Norway University of Applied Sciences, Department of Mechanical and Marine \\ Engineering, Inndalsveien 28, 5063 Bergen, Norway
}

\begin{abstract}
This paper presents an analysis of potential failures of hydraulic components on the example of a hydraulic gear pump with the use of instruments of quality management. The "five why" method was implemented to evaluate failures as well as the bases for the causes which have an influence on pumps failures. The causes are connected with operation condition of gear pumps and the quality of working fluid. In the next step, by using a systematic diagram, appropriate improvement actions for the identified causes were determined.
\end{abstract}

\section{Introduction}

Product defects are almost unavoidable and may occur during the entire life cycle. They may appear already at the design stage or later during operation. When a defect is detected, the most common approach is undertaking an improvement actions, removing incompatibilities and implementing appropriate corrective actions. However, such actions do not include processes of identification of causes of defects, which may lead to defects occurring again. There are various methods of the identification of possible defects, among which quality management methods, such as systematic diagram (decision tool) and the "five why" method might be used. These techniques help to acquire information about a possible (or occurred) defect in a short time and to undertake appropriate improvement actions. They can be used as an independent tool to identify causes and effects of defects or support other methods of quality management including FMEA, KAIZEN or the Ishikawa diagram.

\section{The "five why" method principles}

The "five why" method is one of the methods allowing the identification of the causes of the problem/defect. The method was developed by a Japanese industrialist and inventor Sakichi Toyoda and was used for the first tie in the automotive industry at Toyota. Currently, this method is known all over the world and can be used regardless of the type of business. The "five why" method is one to ask "why" five times, or, if needed, so many

\footnotetext{
*Corresponding author: fabis@mech.pk.edu.pl
} 
times that the cause of the problem is clearly defined, understood and corrective and preventive actions are undertaken. However, quite often the answer to the fifth question determines the cause of the problem. Therefore, this method was named "five why" and it provides the answer to three basic questions [1]:

- why did the problem/defect occurr?

- why wasn't the problem/defect detected?

- how to solve it? - possible application of the systematic diagram.

The analysis of a cause-problem conducted by the "five way" method requires following a few principles:

- correct formulation of the problem/defect to formulate correct questions,

- preserve the sequence of cause and effect relationships,

- each answer is the basis for the next "why" question,

- "why" questions should be asked until the source of defect/problem is detected, the removal of which will eliminate the problem/defect completely so that a similar situation does not happen again in the future,

- "why" questions should be stopped when the answer to the following question are the same or leads to wrong conclusions.

Most often, the "five why" method is used when the problem/defect has already occurred, however, it can also be successfully applied to the analyses aimed at detecting potential problems/defects (those that may still occur). In such a case, preventive measures can be taken or measures that would minimize the problem/defect occurrence by preparing appropriate corrective actions in a proper place and time. The analysis of cause and effect relationships using the "five why" method is conducted in three stages: preparation, analysis and improvement. The first stage of the analysis which is preparation includes:

- Preliminary identification of a problem that has been identified in the object/process.

- Collecting information to create input data for further analysis of the problem, the greater number of collected data, the greater the chance that the cause of the problem will be properly determined.

- Selecting working team and a moderator - employees, experts or clients - anyone who can help determine the causes of the problem correctly. A moderator is a person who controls the whole process, reminds about the problem and monitors the time frame of the analysis.

The second stage of the analysis is a proper analysis, which consists of:

- Naming and describing the problem precisely and finally after the first meeting of the working team. A precisely formulated problem allows the team to focus on important issues and go straight to the root causes of the problem.

- Asking a few questions to help to solve the problem and find the basis for the cause.

- Providing answers - in accordance with the principle of "five why", each answer will be the basis for the following question and for the better understanding of described problem.

When "five why" is completed the final answer is verified whether it is logically related to the problem and if it is based on the principle of cause-and-effect relationships.

The third stage of the analysis is the stage of undertaking improvement actions. If the analysis has dealt with the existing problem the corrective actions are taken. If it is an analysis of potential problems, the preventive actions are formulated and are later monitored. Once the improvement actions are completed, their effectiveness is verified. If the problem still exists despite the implemented actions another "five why" analysis might be necessary to be carried out. The systematic diagram can be used to define improvement actions. 


\section{Systematic diagram}

The systematic diagram is one of the newest quality improvement tools, which is also called a tree diagram, a tree type graph or a decision tree [2]. It is most often used in planning and managing processes in order to predict the consequences of the decisions taken. It can also be used while developing concepts and designing new products to identify possible defects or to improve actions for identified problems. It is therefore, a graphical presentation of necessary activities in a given process or factors affecting the occurrence of a given defect. Additionally, in a logical and chronological way, it describes causes or tasks due to the identified problem/purpose in accordance with the "from general to specific" principle. Fig. 1 presents the method of proceeding when analysing potential defects, with the use of a systematic diagram.

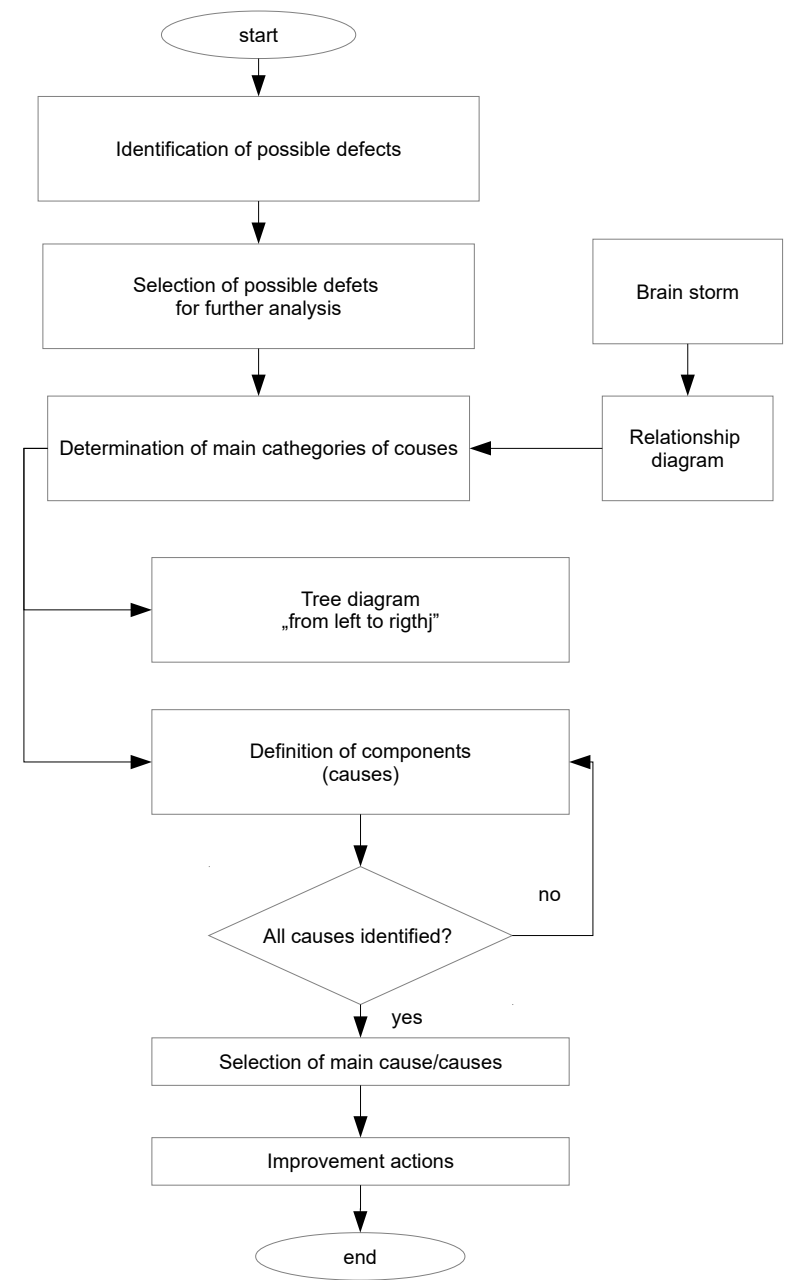

Fig. 1. Algorithm of a systematic diagram.

\section{Analysis of possible defects of a hydraulic gear pump}

One of the most popular hydraulic rotary pumps is a gear pump. The principle of its operation is based on moving the liquid from the suction port to the discharge port between 
the tooth spaces. The gears are meshing in such a way that they separate the suction area from the discharge area at the meshing point [3]. There are several types of gear pumps. They can be distinguished by the shape of the teeth or the number of gears. Hydraulic gear pumps consist of such components as: body, a drive shaft with a keyway, a drive gear, a driven gear, a cover, a bearing, sealing rings, screws, a spring washer and a snap ring. The bearing, drive shaft and gears are those components which are responsible for the proper operation and durability of the entire gear pump and, as a result, affect its efficiency and reliability. However, according to the research [4], about $60 \%$ of failures are caused by the gears. Owing to the use of the "five why" method and the systematic diagram, the causeand-effect relationship was created for the problem of "failure of the gear pump" based on the analysis of the wheel gears.

\subsection{The "five why" method for a gear pump}

Research [5] shows that the wheel gears failure is mainly caused by operational conditions and quality of working fluid. Therefore, the "five why" method was used to identify the main failures in the area of "operation" and "working fluid" for the "gear pump failure" problem. The question-and-answer method provided, in five steps, the information about the source cause in the investigated area.

Problem/effect: gear pump failure (example for operation)

1. Why did the gear pump fail?

Because the gear is damaged.

2. Why is the gear damaged?

Because it has been worn out, cracked and corroded.

3. Why has it been worn out, and why did cracks and corrosion appear?

Because the operating conditions of the gears are incorrect

4. Why are working conditions inappropriate?

Because there were excessive vibrations and contact pressure on teeth.

5. Why did excessive vibrations and contact pressure have occur?

Because there is a small contact area between the teeth and the gears are seized.

The reason for the source: inadequate clearance between the gear wheels

Problem/effect: gear pump failure (example for fluid)

1. Why did the gear pump fail?

Because the gear is damaged.

2. Why is the gear damaged?

Because it has been worn out, cracked and corroded.

3. Why has it been worn, and why did cracks and corrosion appear?

Because of poor quality of a working fluid of or improper properties.

4. Why is the quality of the liquid poor or has improper properties?

Because there are impurities in it or the liquid does not fulfil pump requirements

5. Why is the liquid contaminated or why has it been incorrectly selected?

There were no filters responsible for the quality of the liquid, poor maintenance.

Reason: filters not used, working fluid with improper properties due to poor maintenance instructions.

\subsection{The "five why" method for a gear pump}

The next step of the analysis is creating improvement actions for the identified source reasons and the main problem obtained in the "five why" method. These improvement actions are presented in Fig. 2. 


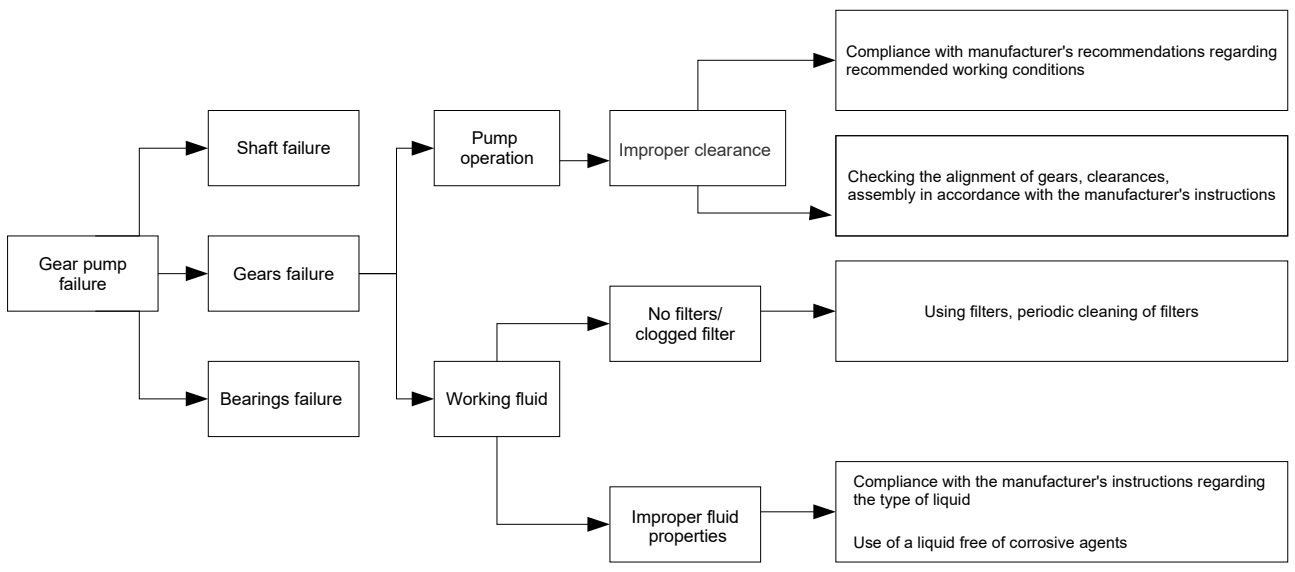

Fig. 2. A systematic diagram for the failure analysis and improvements for a gear pump.

\section{Summary}

The "five why" method supported by the systematic diagram appeared to be an effective tool for identifying potential problems/defects and related causes. It allows to identify areas and causes of failures and specify necessary improvement actions in a relatively short time. Additionally, the details of improvement actions might be obtained by using other tools of quality management, such as an event flow diagram, which determines the sequence of necessary actions. Going further, it should be noted that this method may be especially useful for hard-to-control processes like e.g. biotechnological $[8,9]$, where a biomass may have a wide variation, or machining $[10,11]$, where sources of variability are weakly identified and they may require a specific approach to the uncertainty assessment [12]. It may be also systematically applied in a laboratory scale investigations, if replications have wide variability and it is no idea, what source of variation is a cause e.g. materials science research [13-22], but the greatest impact is achieved at a huge scale enterprises like e.g. large accelerator building [23, 24] or power plants [25]. Such method may be also alternative approach to identify the process factors of the greatest interest in numerical experiments e.g. [26-29] instead of a typical Shainin's approach or factorial screening designs more appropriate for real world experiments with uncontrolled noise factors. Last but not least, it cannot be omitted the applicability of this method in the management area [30-34], where a "human factor" is the greatest noise source.

\section{References}

1. J. Liker, G. Trachilis, Developing Leadership Skills 12: Root Cause-Using The 5 WHY'S (Lean Leadership Inst., Winnipeg, 2014)

2. J. Żuchowski, E. Łagowski, Tools and methods for quality improvements (Wyd. Politechnika Radomska, Radom, 2004)

3. J. Stryczek, Gear wheels of hydraulic machines (Wyd. Politechniki Wrocławskiej, Wrocław, 2007)

4. J.D. Limmer, Wear, 241, 26 (2000)

5. J. Fabis-Domagala, Tribiologia ,2, 33 (2017)

6. P. Pietkiewicz, Techn. Sci., 12, 219 (2009) 
7. S. Haidong, L. Zhiqiang, Q. Lele, Q. Liang, Mech. Syst. Signal Proc., 99, 921 (2018)

8. E. Skrzypczak-Pietraszek, A. Hensel, Pharmazie, 55, 768 (2000)

9. E. Skrzypczak-Pietraszek, I. Kwiecien, A. Goldyn, J. Pietraszek, Phytochem. Lett., 20, 443 (2017)

10. J. Pietraszek, Proc. $11^{\text {th }}$ Int. Conf. on Artificial Intell. and Soft Comp. (ICAISC), Lect. Notes. Artif. Int. 7267, 310 (Zakopane, 2012)

11. E. Lisowski, G. Filo, Flow Meas. Instrum., 53, 269 (2017)

12. J. Pietraszek, M. Kolomycki, A. Szczotok, R. Dwornicka, Lect. Notes Artif. Int., 9875, 260 (2016)

13. T. Pieczonka, J. Kazior, A. Tiziani, A. Molinari, J. Mater. Process. Technol., 64, 327 (1997)

14. M. Ulewicz, U. Lesinska, M. Bochenska, Physicochem. Probl. Mi., 44, 245 (2010)

15. D. Klimecka-Tatar, S. Borkowski, P. Sygut, Arch. Metall. Mater., 60, 735 (2015)

16. M. Ulewicz, E. Radzyminska-Lenarcik, Physicochem. Probl. Mi., 46, 119 (2011)

17. D. Klimecka-Tatar, G. Pawlowska, M. Sozanska, Arch. Metall. Mater., 60, 153 (2015)

18. N. Radek, K. Bartkowiak, Proc. Sixth Int. Wlt Conf. on Lasers in Manufacturing, Physics Procedia, Vol. 12, 499 (Munich, 2011)

19. A. Szczotok, K. Rodak, Proc. Conf. Technol. Properties of Modern Utilised Materials (TPMUM) (Katowice, 2012)

20. R. Ulewicz, P. Szataniak, F. Novy, Proc. 23rd International Conference on Metallurgy and Materials (Brno, 2014)

21. P. Szataniak, F. Novy, R. Ulewicz, Proc. 23rd International Conference on Metallurgy and Materials (Brno, 2014)

22. R. Dwornicka, N. Radek, M. Krawczyk, P. Osocha, J. Pobedza, Proc. 26th Int. Conf. on Metall. and Mater. - METAL (Brno, 2017)

23. B. Singh et al., Eur. Phys. J. A, 52, 325 (2016)

24. B. Singh et al., Nucl. Phys. A, 954, 323 (2016)

25. R. Dwornicka, Adv. Mater. Res.-Switz., 87463 (2014)

26. T. Styrylska, J. Pietraszek, ZAMM-Z. Angew. Math. Mech., 72, T537 (1992)

27. I. Dominik, J. Kwasniewski, K. Lalik, R. Dwornicka, Proc. $32^{\text {nd }}$ Chinese Control Conf. (Xian, China, 2013)

28. J. Pietraszek, A. Gądek-Moszczak, T. Torunski, Adv. Mat. Res.-Switz., 874, 139 (2014)

29. J. Pietraszek, E. Skrzypczak-Pietraszek, Adv. Mat. Res.-Switz., 874, 151 (2014)

30. E. Kozien, Proc. 20 ${ }^{\text {th }}$ Int. Sci. Conf. on Economic and Social Dev. (Prague, 2017)

31. E. Kozien, A. Kozien, Proc. $23^{\text {th }}$ Int. Sci. Conf. on Economic and Social Dev. (Madrid, 2017)

32. E. Kozien, M.S. Kozien, Proc. $26^{\text {th }}$ Int. Sci. Conf. on Economic and Social Dev. Building Resilient Society (Zagreb, 2017)

33. E. Kozien, A. Kozien, Proc. $26^{\text {th }}$ Int. Sci. Conf. on Economic and Social Dev. Building Resilient Society (ESD) (Zagreb, 2017)

34. E. Kozień, Proc. $31^{\text {st }}$ Int. Sci. Conf. on Economic and Social Dev. - Legal Challenges of Modern World (Split, 2018) 